\title{
Meso-scale modelling and radiative transfer simulations of a snowfall event over France at microwaves for passive and active modes and evaluation with satellite observations
}

\author{
V. S. Galligani ${ }^{1}$, C. Prigent ${ }^{1}$, E. Defer ${ }^{1}$, C. Jimenez ${ }^{3}$, P. Eriksson ${ }^{2}$, J.-P. Pinty ${ }^{4}$, and J.-P. Chaboureau ${ }^{4}$ \\ ${ }^{1}$ Laboratoire d'Etudes du Rayonnement et de la Matière en Astrophysique, CNRS, Observatoire de Paris, Paris, France \\ ${ }^{2}$ Department of Earth and Space Sciences, Chalmers University of Technology, Gothenburg, Sweden \\ ${ }^{3}$ Estellus, Paris, France \\ ${ }^{4}$ Laboratoire d'Aérologie, UPS/CNRS, Toulouse, France
}

Correspondence to: V. S. Galligani (victoria.galligani@obspm.fr)

Received: 30 April 2014 - Published in Atmos. Meas. Tech. Discuss.: 16 July 2014

Revised: 9 March 2015 - Accepted: 10 March 2015 - Published: 27 March 2015

\begin{abstract}
Microwave passive and active radiative transfer simulations are performed with the Atmospheric Radiative Transfer Simulator (ARTS) for a mid-latitude snowfall event, using outputs from the Meso-NH mesoscale cloud model. The results are compared to the corresponding microwave observations available from MHS and CloudSat. The spatial structures of the simulated and observed brightness temperatures show an overall agreement since the large-scale dynamical structure of the cloud system is reasonably well captured by Meso-NH. However, with the initial assumptions on the single-scattering properties of snow, there is an obvious underestimation of the strong scattering observed in regions with large frozen hydrometeor quantities. A sensitivity analysis of both active and passive simulations to the microphysical parametrizations is conducted. Simultaneous analysis of passive and active calculations provides strong constraints on the assumptions made to simulate the observations. Good agreements are obtained with both MHS and CloudSat observations when the single-scattering properties are calculated using the "soft sphere" parametrization from Liu (2004), along with the Meso-NH outputs. This is an important step toward building a robust data set of simulated measurements to train a statistically based retrieval scheme.
\end{abstract}

\section{Introduction}

The quantification of the cloud and precipitating frozen phase at a global scale is important to monitor the full Earth energy budget and the hydrological cycle. However, the estimation of the frozen phase (ice and snow) from the present suite of satellite observations is still at a very early stage and remains an important challenge for future satellite instruments. As summarized in Noh et al. (2006), there are two major reasons for this. Firstly, the radiative signatures from falling snow are indistinguishable from liquid water signatures at visible and infrared wavelengths, and they are weak at low microwave frequencies (of $<90 \mathrm{GHz}$ ). At higher microwave frequencies, snowfall characterization from space is a challenging task, but possible through the analysis of the scattering signal from frozen hydrometeors (e.g. Katsumata et al., 2000; Bennartz and Bauer, 2003; Skofronick-Jackson and Johnson, 2011). The second, and main reason, is the complex nature and high variability of the microphysical properties (size, composition, density and shape), and thus radiative properties, of the frozen particles (Johnson et al., 2012). The sensitivity to scattering depends to a large degree on the size and phase of the hydrometeors. In fact, there is a pressing need to constrain such microphysical properties from remote sensing in order to reduce the large uncertainties associated with ice contents in Numerical Weather Prediction and climate models (Waliser et al., 2009; Eliasson et al., 2011). This is crucial to assimilate all-sky radiances. Furthermore, an understanding of the bulk properties of frozen hydrometeors is 
essential to prepare for the next generation of microwave to sub-millimetre observations, i.e. the upcoming ESA MetOpSG satellites with sub-millimetre frequency channels. Robust methods have to be developed to retrieve ice/snow parameters from satellite measurements. These methods are often based on large data sets of simulated observations. The accuracy of the retrieval largely depends on the quality of the simulated database and its representativity. As a first step in the development of such simulated databases, this paper analyses the sensitivity of simulated passive and active microwave observations to the microphysical properties of the frozen phase. The objective is to assess our capacity to simulate passive and active microwave observations in a consistent way for snowfall situations. A meso-scale cloud model (Meso-NH) is coupled with a radiative transfer model (the Atmospheric Radiative Transfer Simulator, ARTS) and run for a real snowfall case. The simulated brightness temperatures (TBs) and equivalent radar reflectivities $\left(Z_{\mathrm{e}}\right)$ are compared to the available microwave observations from the Microwave Humidity Sounder (MHS) and the Cloud Profiling Radar (CPR).

This study is structured as follows. Section 2 presents a heavy snowfall case, and includes a description of Meso-NH model outputs and the coincident satellite observations. Section 3 briefly describes ARTS, along with the recently incorporated radar simulator module and a description of the microphysical properties to be analysed. The sensitivity study of consistent active and passive radiative transfer simulations on such hydrometeor characteristics is presented in Sect. 4. Finally Sect. 5 draws conclusions.

\section{A heavy snowfall event over France: Meso-NH simulations and microwave satellite observations}

\subsection{The meso-scale cloud model: Meso-NH}

The non-hydrostatic mesoscale cloud model Meso-NH (Lafore et al., 1998), jointly developed by Météo-France and the Centre National de la Recherche Scientifique (CNRS), is a research model used in this study to simulate the atmospheric state of a heavy snowfall case over France. Meso-NH performance has been assessed in the past using space-borne sensors at various wavelengths (Chaboureau et al., 2000, 2008; Wiedner et al., 2004; Meirold-Mautner et al., 2007) showing that neither strong nor systematic deficiencies are present in the microphysical scheme and in the prediction of the precipitating hydrometeor contents.

The Meso-NH microphysical scheme developed by Pinty and Jabouille (1998) predicts the evolution of the mixing ratios (mass of water per mass of dry air) of five hydrometeor categories: cloud droplets, rain drops, pristine ice crystals, snowflakes, and graupels. Meso-NH outputs include a full description of the atmospheric parameters (pressure, temperature, and mixing ratios for the water vapour, and the five hydrometeor categories). The multiple interactions operating between the different water species are accounted for through the parametrization of 35 microphysical processes including nucleation, vapour/condensate exchanges, conversion, riming and sedimentation.

Together with the mixing ratios for each hydrometeor category, the intrinsic microphysical scheme to Meso-NH describes some microphysical properties for each particle type at each layer of the atmosphere. This includes parameters such as the particle size distribution (PSD), the intrinsic mass, and the maximum particle diameter.

The concentration of the PSD is parametrized with a total number concentration $N$ given by $N_{\mathrm{h}}=C \lambda_{\mathrm{h}}^{x}$, where the subscript h denotes the hydrometeor category, $C$ and $x$ are empirical constants derived from ground and in situ measurements, and $\lambda_{\mathrm{h}}$ is known as the slope parameter of the size distribution. The size distribution of the hydrometeors is assumed to follow the generalized Gamma distribution,

$$
\begin{aligned}
n(D) \mathrm{d} D & =N_{\mathrm{h}} g(D) \mathrm{d} D \\
& =N_{\mathrm{h}} \frac{\alpha}{\Gamma(\nu)} \lambda_{\mathrm{h}}^{\alpha \nu} D^{\alpha \nu-1} \exp \left(-\left(\lambda_{\mathrm{h}} D\right)^{\alpha}\right) \mathrm{d} D,
\end{aligned}
$$

where $D$ is the maximum dimension of complex shaped particles or the diameter for spherical particles, and $g(D)$ is the normalized distribution, which for $\alpha=v=1$ reduces to the Marshall-Palmer law.

Simple power laws describe the mass-size and the velocity-size relationships,

$m=a D^{b}$

$v=c D^{d}$.

These relationships are taken to perform useful analytical integrations using the moment formula,

$M(p)=\frac{g(p)}{\lambda_{\mathrm{h}}^{p}}=\frac{1}{\lambda_{\mathrm{h}}^{p}} \frac{\Gamma(\nu+p / \alpha)}{\Gamma(v)}$,

where $M(p)$ is the $p$ th moment of $g(D)$. Equation (4) can be used to compute the different hydrometeor mixing ratios $q_{\mathrm{h}}$ according to

$\rho_{\mathrm{h}} q_{\mathrm{h}}=\int_{0}^{\infty} m(D) n(D) \mathrm{d} D=a N_{\mathrm{h}} M_{\mathrm{h}}(b)$,

where $\rho_{\mathrm{h}}$ is the density of dry air. Table 1 describes the constants that characterize each of the hydrometeor species in the above-mentioned relations.

\subsection{The case study}

The selected scene corresponds to a strong snowfall event over France, 8 December 2010, very early in the cold season. This meteorological event led to huge disruptions of the 
Table 1. Parameters of the Meso-NH microphysical scheme described by Eqs. (1)-(5) (given in MKS units).

\begin{tabular}{lcccccccc}
\hline Category & $\alpha$ & $v$ & $a$ & $b$ & $c$ & $d$ & $C$ & $x$ \\
\hline$q_{\mathrm{c}}$ (cloud) & 3 & 3 & 524 & 3 & $3.2 \times 10^{7}$ & 2 & & \\
$q_{\mathrm{i}}$ (ice) & 3 & 3 & 0.82 & 2.5 & 800 & 1 & & \\
$q_{\mathrm{s}}$ (snow) & 1 & 1 & 0.02 & 1.9 & 5.1 & 0.27 & 5 & 1 \\
$q_{\mathrm{g}}$ (graupel) & 1 & 1 & 19.6 & 2.8 & 124 & 0.66 & $5 \times 10^{5}$ & -0.5 \\
$q_{\mathrm{r}}$ (rain) & 1 & 1 & 524 & 3 & 824 & 0.8 & $10^{7}$ & -1 \\
\hline
\end{tabular}
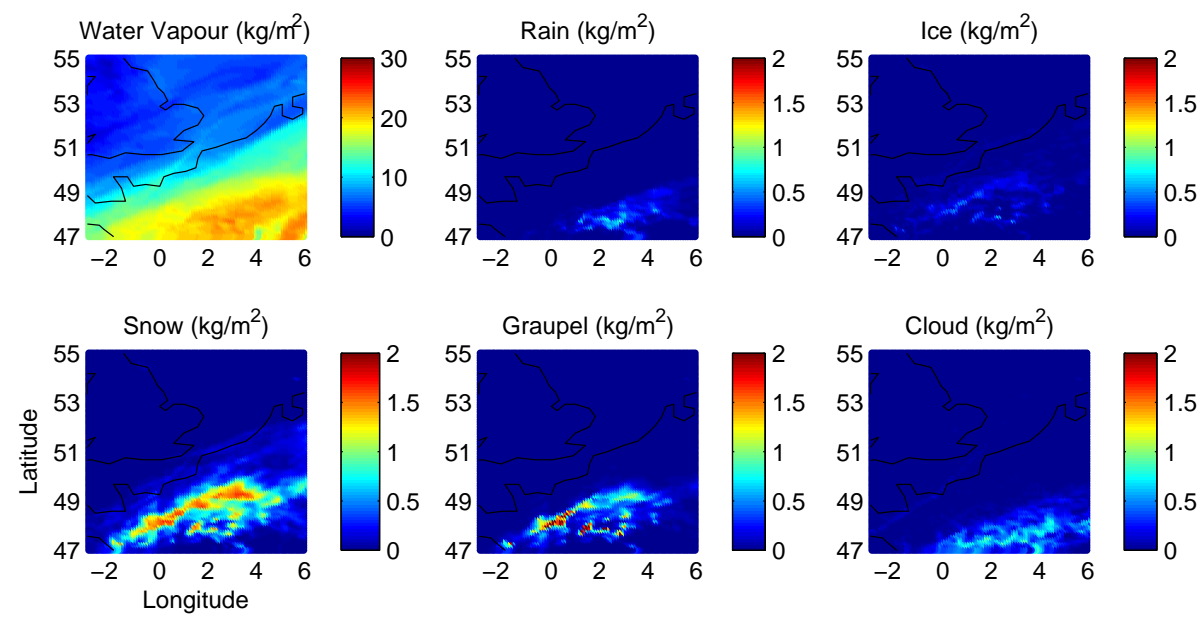

Figure 1. The Meso-NH fields at 13:00 UTC of the heavy snowfall scene over France on 8 December 2010. Coincident observations from MHS and CloudSat are available.

transportation network over a large part of France, especially in the areas of Paris.

Meso-NH was initialized using ECMWF analysis from 8 December 2010 at 00:00 UTC and run with lateral boundary conditions linearly interpolated from the ECMWF 6hourly analyses (successively taken at 06:00, 12:00 UTC, etc.). The simulation domain contains $192 \times 192$ grid points at $20 \mathrm{~km}$ resolution, centred approximately in Paris. A second model at $5 \mathrm{~km}$ resolution with $256 \times 256$ grid points is gridnested and centred at the same place. Both domains contain a vertical grid with 48 levels unevenly spaced, with layer thickness varying from $50 \mathrm{~m}$ close to the surface and up to $1000 \mathrm{~m}$ at the top of the atmosphere.

Meso-NH model outputs are available every hour for this scene and the outputs at 13:00 UTC, corresponding to the over-pass of satellites onboard the A-train mission and NOAA-18, are analysed in this study. Figure 1 presents the total columns of water vapour, cloud, rain, graupel, snow and ice, as simulated by Meso-NH at 13:00 UTC. The case is associated with a broad pattern of moderate to heavy rainfall of a few $\mathrm{mm} \mathrm{h}^{-1}$. Maximum accumulated rainfall and snowfall of 30 and $5 \mathrm{~mm}$, respectively, has been measured over the whole event in northern and central France, with intensities of a few millimetres per hour (up to $5 \mathrm{~mm} \mathrm{~h}^{-1}$ for rain and $1 \mathrm{~mm} \mathrm{~h}^{-1}$ for snow).

\subsection{Coincident satellite observations}

This study focuses on high-frequency microwave radiative transfer simulations and their evaluation with coincident passive and active observations. As mentioned earlier, the Atrain mission and NOAA-18 over-passed the region modelled by Meso-NH at approximately 13:00 UTC. The satellite instruments of interest here are MHS (Bonsignori, 2007) onboard NOAA-18 and the CPR radar (Stephens et al., 2002) onboard CloudSat, a satellite on the A-train constellation.

MHS is a cross-track humidity sounder with surface zenith angles varying between 0 and $58^{\circ}$. The channels are located at $89.0,157.0,183.3 \pm 1,183.3 \pm 3$ and $190.3 \mathrm{GHz}$. The channels near the water vapour line of $183.3 \mathrm{GHz}$ are opaque because of atmospheric absorption, in contrast to the more transparent window channels at 89,157 and $190 \mathrm{GHz}$. The spatial resolution at nadir is $16 \mathrm{~km}$ for all channels and increases away from nadir $(26 \mathrm{~km}$ at the furthest zenith angle along track). The polarization state is variable and results from a combination of the two orthogonal linear polarizations $(\mathrm{V}$ and $\mathrm{H})$, with the polarization mixing depending on the scanning angle. The CPR onboard CloudSat is a $94 \mathrm{GHz}$ nadir-looking radar that measures the power backscattered by cloud and precipitating particles as a function of distance from the radar. It has a footprint of $1.4 \mathrm{~km}$ (cross-track) and $1.7 \mathrm{~km}$ (along-track). The CPR minimum detectable signal is 
approximately $-30 \mathrm{dBZ}$. The standard product, supplied as 2B-GEOPROF (Mace, 2007), is the radar reflectivity with a resolution of $240 \mathrm{~m}$ in the vertical. CloudSat overflew France at 12:55 UTC and MHS observed the scene approximately $20 \mathrm{~min}$ later. This represents an interesting opportunity to analyse the responses of both active and passive instruments under snowfall conditions.

\section{Radiative transfer (RT) simulations}

\subsection{Simulating passive observations with ARTS}

Radiative transfer (RT) simulations were performed with ARTS (Eriksson et al., 2011). ARTS is a freely available, well documented, open source software package that is well validated (Melsheimer et al., 2005; Buehler et al., 2006; Saunders et al., 2007). ARTS handles scattering with a full and efficient account of polarization effects. It provides different methods to solve the radiative transfer equation and the reverse Monte Carlo method (Davis et al., 2007) is used in this study.

The RT simulations take full account of the 3-D description of the atmospheric state modelled by Meso-NH. In order to accurately simulate satellite observations of this real scene, a correct description of the surface properties is important, especially for microwave frequency channels away from the water vapour absorption line at $183.3 \pm 3 \mathrm{GHz}$. For this reason, the Tool to Estimate Land Surface Emissivities at Microwave Frequencies (TELSEM; Aires et al., 2011) is used over land. TELSEM provides the emissivity (V and $\mathrm{H}$ components) for any location, any month, and any incidence angle. It is based on the analysis of the frequency, angular and polarization dependence and it is anchored to the emissivities calculated from SSM/I observations. Similarly, the Fast Microwave Emissivity Model (FASTEM; Liu et al., 2011) is used for ocean emissivities. FASTEM calculates sea surface emissivities from wind, sea surface temperature and viewing angle.

\subsection{The cloud radar simulator incorporated into ARTS}

The equivalent radar reflectivity factor $\left(Z_{\mathrm{e}}\right)$ is the main quantitative parameter measured by radar instruments. In the absence of attenuation, the equivalent radar reflectivity factor $Z_{\mathrm{e}}$ is given by integrating the backscatter cross-sections of the individual particles over their size distribution:

$Z_{\mathrm{e}}=\frac{\lambda^{4}}{\pi^{5}\left|K_{w}\right|^{2}} \int_{0}^{\infty} \sigma_{\mathrm{b}}(D) n(D) \mathrm{d} D$,

where $\lambda$ is the radar wavelength, $\left|K_{w}\right|^{2}$ is the reference dielectric factor (a value of 0.75 is generally used for CloudSat), $\sigma_{\mathrm{b}}$ is the backscatter cross-section and $n(D)$ is the particle size distribution.
Recently, a module has been added to ARTS that allows the simulation of cloud radar observations. The module is part of the open source ARTS development version described in Sect. 3.1. Since Eq. (6) is calculated using the singlescattering properties in the same format as applied for passive observations, this module ensures a basic consistency in the microphysics assumptions independent of the technique simulated whether active or passive. Note that the module considers the two-way attenuation by gases and hydrometeors, and that multiple scattering is ignored. The single-scattering assumption is a frequently accepted simplification for precipitation and cloud radar observations, although at high microwave frequencies Battaglia et al. (2008) showed that multiple scattering can significantly enhance the reflectivity profiles as observed at $94 \mathrm{GHz}$ with CloudSat.

For a more detailed description of this ARTS radar module, refer to the ARTS Development Version User Guide (Chapter 19 in http://www.sat.ltu.se/arts/misc/arts-doc/ uguide/arts_user.pdf). Equation (6) is also used in the Quickbeam radar forward model (Haynes et al., 2007). The main difference between ARTS and Quickbeam is that the latter runs with pre-defined Mie tables or on-the-fly calculations based on a number of in-built choices for size distributions, phase and mass-size diameter. In contrast, the ARTS radar module defines externally the single-scattering properties and the particle size distribution. Note that the radar simulations are calculated in reference to the CloudSat altitude bin resolution (125 vertical bins $240 \mathrm{~m}$ thick).

\subsection{The hydrometeor scattering properties}

The microphysical properties of the five hydrometeor categories inherent in Meso-NH, i.e. cloud, rain, ice, snow and graupel, are externally incorporated into ARTS via their particle size distribution and single-scattering properties. The scattering properties of hydrometeors are related to their composition and density (and related dielectric properties), their size, their shape and their orientation. Our analysis focuses on the evaluation of the impact and validity of different microphysical parameters in radiative transfer simulations by comparing them with the available passive and active observations.

1. Density and shape: hydrometeor shapes, and consequently volume and density, are not explicitly specified by meso-scale models like Meso-NH. For this reason, crucial parameters in radiative transfer calculations via the scattering properties, remain free parameters and assumptions are needed. As introduced in Sect. 2.1, the mass of each hydrometeor category in Meso-NH is derived from the mass-size relation (of the type $m=$ $\left.a D^{b}\right)$. For liquid clouds and rain, the particles are assumed to be spheres since $m$ is proportional to $D^{3}$. Although the shapes of graupel and small ice crystals are not defined strictly as spheres by Meso-NH $(b=2.8$ and 
$b=2.5$, respectively), they are approximated as such in the radiative transfer simulations of this study together with liquid cloud and rain. Graupels are rimmed particles for which it is reasonable to assume a spherical shape. Small pure ice crystals can be approximated by spheres for microwave radiative transfer calculation as their scattering is very limited. Snow particles, however, are not spheres, with mass $m$ proportional to $D^{1.9}$. While liquid cloud, rain, graupel and ice crystal shapes are held fixed to be spheres unless otherwise stated, this study explores assumptions on snow particle shape, and consequently snow density. A common approach in both active and passive simulations is not to describe the precise individual particle shapes, but to determine the overall shape of the particles as determined by the aspect ratio (Dungey and Bohren, 1993; Matrosov et al., 2005; Hogan et al., 2012). From multiple aircraft observations, A. Heymsfield, personal communication, 2012) confirms the importance of the bulk shape of particles as characterized by their aspect ratio, neglecting the microwave passive simulation of individual complicated particle shapes. Aspect ratios (longest/shortest axis of ellipse) of the order of 1.6 are investigated, as suggested in Korolev and Isaac (2003), Hanesch (2009), Matrosov et al. (2005) and A. Heymsfield, personal communication, 2012). In terms of density, the particle density for ice crystals is that of pure ice (0.917) and for snow and graupel, it is derived from the Meso-NH mass-size relationship and the assumed particle shape.

2. Dielectric properties: for pure water, the dielectric properties in the microwave region are computed with limited uncertainties - for instance, using Liebe et al. (1991). For pure solid ice, there are a number of different parametrizations. In this study, the Mätzler (2006) model is used, as it is based on a detailed review of the previous measurements and models. Note that any uncertainties arising from the dielectric properties assumed for pure ice are not of direct concern in this study, as the magnitude of such errors is much smaller than uncertainties due to size, composition or shape. The accuracy of liquid water absorption models in the microwave for supercooled liquid (i.e. liquid water at less than $0^{\circ} \mathrm{C}$ ) is, however, uncertain, with differences up to $10 \mathrm{~K}$ between different absorption models especially at the higher window frequencies (Kneifel et al., 2014). For frozen species other than pure solid ice such as graupel or snow, particles can be considered as homogeneous mixtures of ice/air, or possibly ice/air/liquid water. For such mixtures, density becomes a key parameter in the calculation of dielectric properties. The dielectric properties can then be deduced from a number of mixing formulas. Only one mixing formula is considered here: the Garnett (1906) formulation (hereafter $\mathrm{MG})$, which describes the effective dielectric constant of the mixed media as a function of the matrix $\left(\epsilon_{\mathrm{m}}\right)$ and inclusion $\left(\epsilon_{\mathrm{i}}\right)$ dielectric constants:

$\epsilon_{e}=\epsilon_{\mathrm{m}}+3 f_{\mathrm{i}}^{\mathrm{v}} \epsilon_{\mathrm{m}} \frac{\left(\epsilon_{\mathrm{i}}-\epsilon_{\mathrm{m}}\right)}{\epsilon_{\mathrm{i}}+2 \epsilon_{\mathrm{m}}-3 f_{\mathrm{i}}^{\mathrm{v}}\left(\epsilon_{\mathrm{i}}-\epsilon_{\mathrm{m}}\right)}$

and where $f_{\mathrm{i}}^{\mathrm{v}}$ is the volume fraction of the inclusion of the medium. Under the MG formulation, dry snow can be described as a two-phase mixture of ice and air, and wet snow can be described by applying Eq. (7) twice for a two-phase mixture of water inclusions in an ice/air matrix. Note that the MG formulation is not symmetric with respect to the two media, i.e. the "ice in air" $\left(\mathrm{MG}_{\mathrm{IA}}\right)$ is not equal to the "air in ice" $\left(\mathrm{MG}_{\mathrm{AI}}\right)$. Both dry snow (with ice inclusions in an air matrix, $\mathrm{MG}_{\mathrm{IA}}$ ) and wet snow are here studied. For dry snow, the volume fraction is $f_{\mathrm{i}}^{\mathrm{v}}=\rho$ (snow) $/ \rho$ (ice), where $\rho$ (snow) is the density of snow and graupel as deduced from the Meso-NH mass-size relationships. In the case of wet snow, the volume fraction of water inclusions gives an indication often referred to as the wetness degree.

An important remark should be made here concerning the choice of mixing rules. Uncertainties arising from the choice of mixing rules are not considered in this study. Johnson et al. (2012) studied the resulting differences in mixing rule choice, specifically between the two best-known rules which are the effective medium approximation or the Bruggeman (1935) and the matrix inclusion method or the MG formulation. The differences are quantified to be of minor importance $(>1.5 \mathrm{~K}$ and $<0.3 \mathrm{~dB}$ ) for frequencies between 2.8 and $150 \mathrm{GHz}$ when $\mathrm{MG}_{\mathrm{IA}}$ formulation is used. The differences become significant between the two MG versions (at least $10 \mathrm{~K}$ and approximately $2 \mathrm{~dB}$ ).

3. Single-scattering properties: the single-scattering properties are calculated with the $\mathbf{T}$-matrix code developed by Mishchenko (2000), which enables the treatment of spherical and non-spherical particles, as well as randomly and horizontally oriented particles. Another approach is to calculate the single-scattering properties of complex shapes with the discrete-dipole approximation (DDA; Purcell and Pennypacker, 1973). The DDA method can be used for arbitrary sized, shaped and oriented particles. Despite complicated non-spherical particles having more realistic shapes, their generation depends on idealized models that do not fully capture the large variability observed in nature. In the calculations here, the frozen particles are described by spheroids and their scattering properties are calculated from their bulk properties, i.e. dielectric properties, size and aspect ratio. This allows the use of the efficient T-matrix method. Since the spherical approximation is not always adequate for complicated aggregates (e.g. Kim, 2006; 

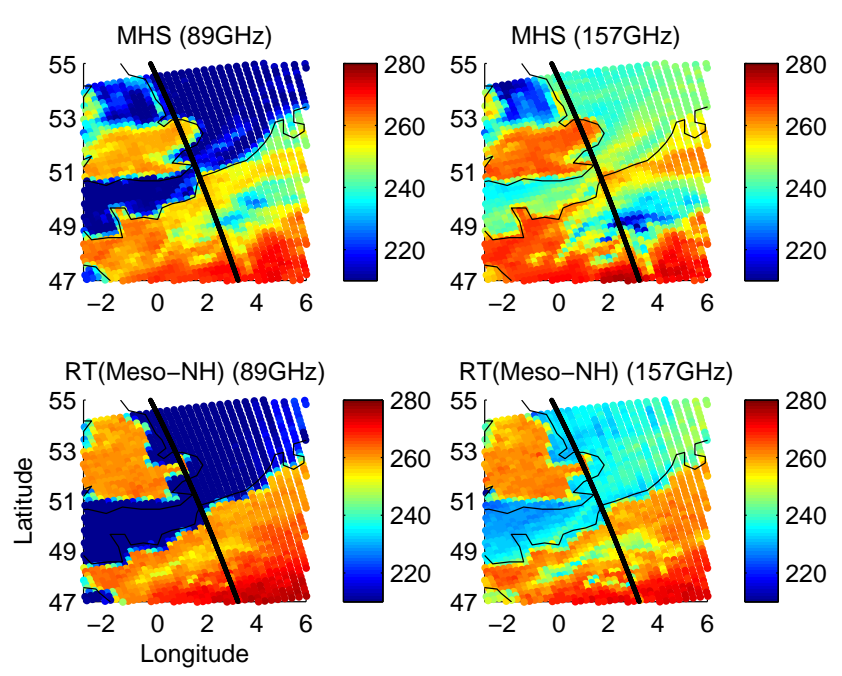

Figure 2. MHS observations at 89 and $157 \mathrm{GHz}$ (top panel), as compared with the corresponding simulated brightness temperatures with the microphysical scheme intrinsic to Meso-NH (bottom panel). The solid black line illustrates the CloudSat track.

Meirold-Mautner et al., 2007; Kulie et al., 2010; Nowell et al., 2013), we also explore an approach formulated by Liu (2004) in which the single-scattering properties of aggregates are parametrized based on DDA modelling. Liu (2004) notes that sector-like and dendrite snowflakes have scattering and absorption properties between those of a solid ice equal-mass sphere of diameter $D_{0}$ and an ice-air mixed sphere with a diameter equal to the maximum dimension of the particle $D_{\max }$. The dielectric properties of snow are then described by the Maxwell-Garnett mixing formula and the diameter of the ice equal-mass sphere is described by a softness parameter $\mathrm{SP}=\left(D-D_{0}\right) /\left(D_{\max }-D_{0}\right)$. The frequencydependent softness parameter (SP) gives the diameter of the best-fit equal-mass sphere, i.e. a frequency dependent effective density and a modified diameter is used to calculate the single-scattering properties with the Tmatrix. This approach has already shown a high efficiency in reproducing real observations (e.g. MeiroldMautner et al., 2007) and it is tested here.

\section{Comparison of the simulations with coincident observations}

\subsection{The observed and simulated scene}

A close examination of MHS observations from the scene of interest (top panels of Fig. 2) and the Meso-NH outputs in Fig. 1 (and the hourly Meso-NH outputs not shown here) reveals that the cloud system modelled by Meso-NH, evidenced by its brightness temperature depressions in the window channels of MHS, is slightly time lagged with respect to the observations. The global structure of the cloudy scene,
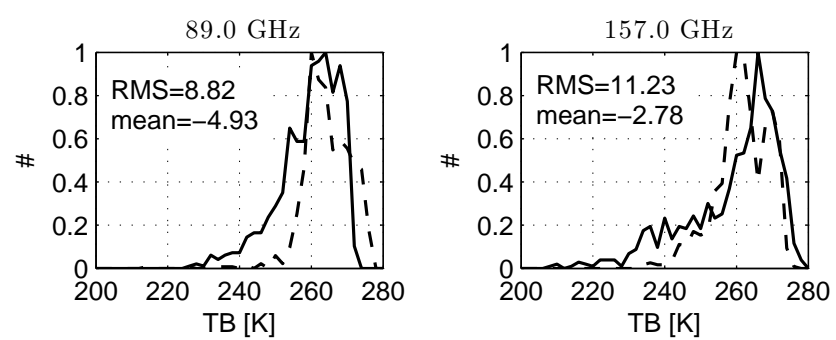

Figure 3. Histograms of the observed (solid line) and simulated (dashed line) MHS brightness temperatures at 89 and $157 \mathrm{GHz}$ with the Meso-NH microphysical scheme. The data used to calculate these distributions correspond to cloudy pixels (as determined my Meso-NH) over land as presented in Fig. 2. The rms and bias of the difference between the two are indicated for each frequency.

however, is fairly well modelled by Meso-NH, in agreement with its location in the observations. With this in mind, the objective of the radiative transfer simulations is to successfully reproduce the brightness temperature depressions related to the frozen phase of the cloud. It is not to simulate the detailed spatial structure of the observations: differences in time between the simulations and the observations (although small), added to the uncertainties in the detailed spatial structure of the front with Meso-NH, would make this task unrealistic.

The first step in the radiative transfer simulations is to stay as consistent as possible with Meso-NH. In order to do this, the microphysical description of hydrometeors from Meso$\mathrm{NH}$ is first used. The mass-size relationships and the particle size distributions described in Sect. 2.1 (Eqs. 1 and 2) are adopted for the five species provided by Meso-NH (rain, cloud, ice, snow and graupel) and all hydrometeors are considered spherical. The dielectric properties of rain, liquid cloud and ice are described in Sect. 3.3. The resultant brightness temperatures from these microphysical assumptions are shown in Fig. 2 (bottom) as compared with the corresponding MHS observations (top). With these hypotheses, the scattering signal appears significantly less intense in the simulations, failing to reproduce the observed signal. This simulation will be referred to as the baseline configuration.

Figure 3 shows the distribution of the observed and simulated pixels presented in Fig. 2. Note that only pixels over land and flagged as cloudy according to a Meso-NH cut-off flag $\left(0.05 \mathrm{~kg} \mathrm{~m}^{-2}\right)$ are included in the distributions. The statistical distributions show that for 89 and $157 \mathrm{GHz}$, observations are mostly sensitive to the snow mass column and the distribution of simulated brightness temperatures is shifted towards higher brightness temperatures (i.e. failing to reproduce the intense scattering that translates into the observed brightness temperature depressions).

The radiative transfer simulations presented so far in Fig. 2 and Fig. 3 fail to reproduce the observed scattering signatures because either (1) the amount of frozen particles produced 


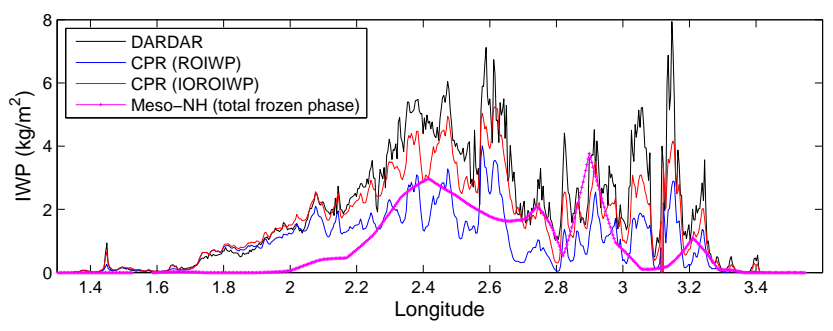

Figure 4. CloudSat CPR ice mass content as retrieved by DARDAR, CWC-RO and CWC-IO-RO. The total frozen mass contents (graupel + ice + snow) modelled by Meso-NH are shown for reference.

by Meso-NH simulations is underestimated, or (2) there is a misrepresentation of the scattering properties of the frozen phase, more specifically of snow species, in the RT simulations in terms of dielectric properties, effective size and shape.

To test these two possibilities, the availability of coincident CloudSat observations can be exploited. CloudSat observations allow comparing its different retrieved ice water path (IWP) with those modelled by Meso-NH for the CloudSat footprint, as shown in Fig. 4. In order to carry out this comparison, the three frozen species from Meso$\mathrm{NH}$ are summed (ice, graupel and snow) along the CloudSat footprint and compared with three different retrieval algorithms. The ROIWP product is one of CloudSat standard products and is available from the 2B-CWC-RO data set. ROIWP is the radar only (RO) retrieved value of IWP, obtained by assuming that the entire profile is ice, and zeroing out cases where all cloudy bins are warmer than $273 \mathrm{~K}$ (assumed to be liquid). The IOROIWP, similarly available from the 2B-CWC-RO data set, assumes that the entire column is ice only. DARDAR exploits lidar/radar synergy onboard the A-Train. The CPR radar can penetrate thick systems of precipitating clouds, but is mainly sensitive to large particles and does not detect small ones. The CALIOP lidar, on the other hand, is sensitive to smaller particles, but gets attenuated quickly. Therefore radar/lidar DARDAR approach (Delanoë and Hogan, 2008, 2010) is complementary. Despite retrieved IWP having large errors, reported by Austin et al. (2009) to be around $40 \%$, this qualitative comparison gives an idea of the performance of the Meso- $\mathrm{NH}$, with three different retrieved products including DARDAR. Neglecting the fine structures of the CloudSat products, Meso-NH total IWP is comparable between 2.8 and $2.9^{\circ} \mathrm{W}$ (mainly due to the strong presence of graupel). In the region between 2.3 and $2.5^{\circ} \mathrm{W}$, Meso- $\mathrm{NH}$ is comparable to the IROIWP retrieval. Overall, however, the Meso-NH outputs tend to underestimate the total IWP when compared with CloudSat retrievals. This is not surprising given the difficulties in modelling the frozen phase, and the mentioned time lag between Meso-NH model outputs and the observations.
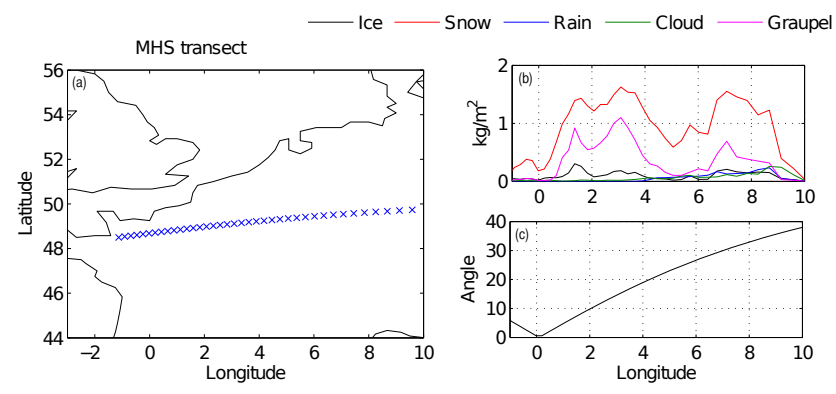

Figure 5. Selected transect of the case study: (a) the location of the transect; (b) the integrated content of the different Meso-NH hydrometeors along this transect; and (c) the incidence angle of the MHS observations along the transect.
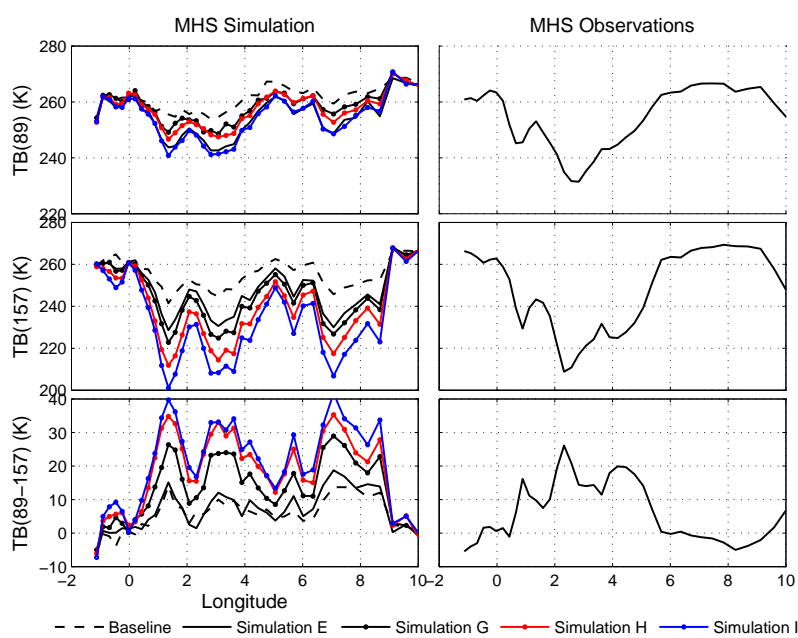

Figure 6. The observed (right) and the simulated (left) brightness temperature measurements from the MHS windows channels along the transect of interest presented in Fig. 5. See Table 2 for more information on each of the simulations illustrated.

In an attempt to produce more scattering, the simulations in Fig. 2 are re-considered with the snow content in Meso$\mathrm{NH}$ multiplied by 1.25 in each layer. This value is chosen from the analysis of Fig. 4 in order to level Meso-NH outputs with the CloudSat retrievals. The ability of Meso-NH to simulate the different hydrometeors is discussed in the following section. For now, multiplying the Meso-NH snow content by 1.25 does not change the results by more than $1 \mathrm{~K}$ along the transect. This means that the microphysical properties require further study. The microphysical parameters describing snow particles are subject to many uncertainties, originating from the microphysical scheme of Meso-NH or from the interpretation of the Meso-NH information in terms of scattering efficiency. To answer this question we proceed to analyse the sensitivity of active and passive simulations. 
Table 2. A description of the different microphysical assumptions made in the radiative transfer simulations presented. The baseline simulation consists of using the Meso-NH microphysical scheme and assuming that snow and graupel species are perfect spheres and that their dielectric properties are defined by the dry snow approach. The effect of the different simulations is here presented as the maximum TB depression at $157 \mathrm{GHz}$ along the transect, where the $\mathrm{TB}$ depression is defined as $\mathrm{TB}_{\text {clear }}-\mathrm{TB}_{\text {simulation }}$, which should be compared with the max TB depression observed by MHS at $157 \mathrm{GHz}$ of $62 \mathrm{~K}$.

\begin{tabular}{|c|c|c|c|}
\hline Simulation & Settings & $\begin{array}{c}\text { Effect }(\max . \mathrm{TB} \\
\text { depression }(\mathrm{K}) \text { at } 157 \mathrm{GHz})\end{array}$ & $\begin{array}{l}\text { Representation } \\
\text { Fig. } 6\end{array}$ \\
\hline Baseline & Meso-NH, dry snow, sphere & 18 & $\begin{array}{l}\text { Black dashed line } \\
\text { (also shown in Fig. 7a) }\end{array}$ \\
\hline A & $\begin{array}{l}\text { Meso-NH, dry snow, sphere, } \text { PSD }_{\text {snow }} \\
\text { described by } \text { PSD }_{\text {graupel }}\end{array}$ & 21 & Not shown \\
\hline B & $\begin{array}{l}\text { Meso-NH, dry Snow, horizontally } \\
\text { aligned spheroids, ar }=1.6\end{array}$ & 21 & Not shown \\
\hline $\mathrm{C}$ & Meso-NH, wet snow, sphere & 19 & Not shown \\
\hline $\mathrm{D}$ & Meso-NH, dry snow, $\rho=0.1 \mathrm{~g} \mathrm{~cm}^{-3}$, sphere & 30 & Not shown \\
\hline $\mathrm{E}$ & $\begin{array}{l}\text { Meso-NH, dry snow, } \rho=0.1 \mathrm{~g} \mathrm{~cm}^{-3} \\
\text { horizontally aligned spheroids, ar }=1.6\end{array}$ & 31 & $\begin{array}{l}\text { Black solid line } \\
\text { (also shown in Fig. 7a) }\end{array}$ \\
\hline $\mathrm{F}$ & $\begin{array}{l}\text { Meso-NH, dry snow, } \rho=0.1 \mathrm{~g} \mathrm{~cm}^{-3} \\
\rho_{\text {graupel }}=0.4 \mathrm{~g} \mathrm{~cm}^{-3}\end{array}$ & 84 & Not shown \\
\hline G & $\begin{array}{l}\text { Meso-NH, dry snow, } \rho=0.1 \mathrm{~g} \mathrm{~cm}^{-3} \\
\text { horizontally aligned spheroids, ar }=1.6 \\
\text { PSD }_{\text {snow }} \text { described by } \text { PSD }_{\text {graupel }}\end{array}$ & 37 & Black dotted line \\
\hline $\mathrm{H}$ & $\begin{array}{l}\text { Meso-NH, dry Snow, horizontally } \\
\text { aligned spheroids, ar = 1.6, } \\
\text { approximation from Liu (2004) }\end{array}$ & 48 & $\begin{array}{l}\text { Red dotted line } \\
\text { (also shown in Fig. 7c) }\end{array}$ \\
\hline I & $\begin{array}{l}\text { Simulation } \mathrm{H} \text { with } \\
\text { IWC }_{\text {snow }} \mathrm{X} 1.25\end{array}$ & 59 & $\begin{array}{l}\text { Blue dotted line } \\
\text { (also shown in Fig. 7f) }\end{array}$ \\
\hline
\end{tabular}

\subsection{Evaluation of active and passive simulations: a detailed analysis along a transect}

In this section we analyse the sensitivity of the RT simulations to different microphysical assumptions of the frozen phase, focussing on the CloudSat footprint and a specific transect as described in Fig. 5. The latter transect corresponds to a specific MHS scan from close to nadir to its outermost angle north, and it is characterized by the dominance of snow in the Meso-NH outputs (Fig. 5b). The objective is to reproduce consistently the brightness temperature depressions related to the frozen phase of the cloud and the radar reflectivity with realistic microphysical properties. Again, it is not to simulate the detailed spatial structure of the observations.

The microphysical description of the hydrometeors from Meso-NH (see the baseline simulation in Fig. 2) is the starting point for the radiative transfer simulations (the black dashed line in Fig. 6). Consistent with Fig. 2, this baseline simulation fails to reproduce intense scattering. Starting from the initially selected parameters, different configurations were run. Table 2 summarizes the results of different tests along the transect of interest and provides the maximum brightness temperature (TB) depression at $157 \mathrm{GHz}$. Some of these results are shown in Fig. 6.

The following assumptions have been tested one at a time: (a) the intrinsic Meso-NH snow size distribution was replaced by the intrinsic Meso-NH particle size distribution of graupel, (b) perfect snow spheres were replaced by horizontally aligned spheroids of aspect ratio 1.6, (b) the dielectric properties of snow species were calculated with the Maxwell-Garnett mixing formula but with different wetness degrees according to a wetness degree $W(\%)=0$ for $T<258.15 \mathrm{~K}, W(\%)=T-258.15$ for $258.15 \mathrm{~K}<T<273.15 \mathrm{~K}$, and $W(\%)=15$ for $T<273.15 \mathrm{~K}$ from Skofronick-Jackson et al. (2002). All these microphysical assumptions failed to change significantly the simulated brightness temperatures by more than $5 \mathrm{~K}$ along the transect at $157 \mathrm{GHz}$ as detailed in Table 2. As mentioned above, Table 2 is used in this section to illustrate the sensitivities being studied by providing the maximum brightness temperature (TB) depression at $157 \mathrm{GHz}$, i.e. the difference between $\mathrm{TB}_{\text {clearsky }}$ and the simulation, along the transect of interest, 

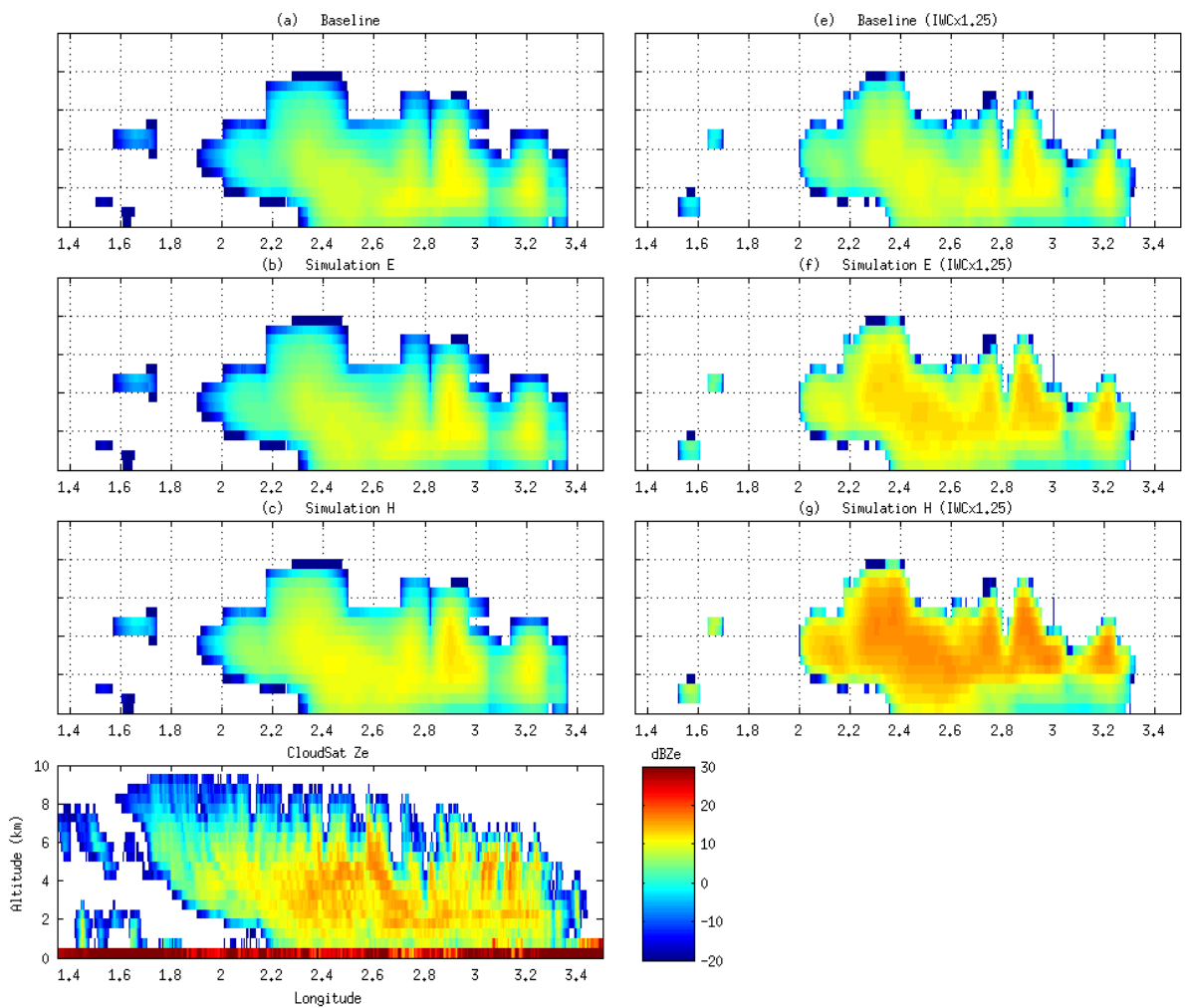

Figure 7. The simulated CPR $(94 \mathrm{GHz})$ radar reflectivity is shown in panels (a)-(f). See Table 2 for more information on each of the simulations illustrated. The CloudSat CPR radar reflectivity $(94 \mathrm{GHz})$ is also shown in (g) downscaled to the Meso-NH resolution for reference.

so as to avoid clutter in Fig. 6. Of importance here is that similarly to the conclusions drawn in Meirold-Mautner et al. (2007), snow particles that are likely to scatter radiation at 89 and $157 \mathrm{GHz}$ have very low density under the Meso-NH mass-size relationship, and as a consequence they are mostly composed of air and have a very limited impact on the signal.

Changing the density of snow to a fixed value of $0.1 \mathrm{~g} \mathrm{~cm}^{-3}$, a value often used in weather model microphysical schemes for snow (i.e. Thompson et al., 2004), leads to a significant depression of the brightness temperatures (D in Table 2). Similar results are obtained with horizontally aligned spheroids of aspect ratio 1.6 (simulation E in Table 2 and solid black line in Fig. 6). So far the density for graupel was parametrized according to Meso-NH. Setting the graupel density to a fixed value of $0.4 \mathrm{~g} \mathrm{~cm}^{-3}$, a value often used in weather model microphysical schemes (simulation $\mathrm{F}$ in Table 2), yields brightness temperatures that are much lower than those observed by MHS.

To assess the impact of the PSD on the radiometric signals for the configuration that shows good consistency with the simulations and the physical sense (snow horizontally aligned spheroids with a fixed density of $0.1 \mathrm{~g} \mathrm{~cm}^{-3}$ and graupel species as parametrized with Meso-NH, i.e. simulation E in Table 2), the Meso-NH snow PSD was replaced by Meso-NH PSD of graupel for spherical particles with fixed density (simulation $\mathrm{G}$ in Table 2 and black dotted line in Fig. 6). The particle size distribution of graupel assumes fewer larger particles, and more abundant smaller particles. This causes large brightness temperature depressions.

Finally, the approach suggested by Liu (2004) to approximate the single-scattering properties of snow species calculated with the DDA method is analysed. As shown in Fig. 6, the results are very encouraging in accordance with the observed TBs (simulation $\mathrm{H}$ in Table 2 and red dotted line in Fig. 6). Analysing the sensitivity of these assumptions to the snow content by multiplying it by 1.25 each atmospheric layer shows that the improvement is not significant in terms of brightness temperatures (simulation I in Table 2 and blue dotted line in Fig. 6).

The CloudSat response is then simulated based on the analysis conducted for the passive simulations. Figure 7 (left column) presents the active simulations using the coincident Meso-NH species contents as shown in Fig. 4. The first step was to simulate the active response assuming the initial microphysical properties from the Meso-NH scheme (the baseline configuration), which proved to underestimate the scattering efficiency for passive radiative transfer simulations. The results are shown in Fig. 7a for perfect spheres. The overall 2-D structure of the observed reflectivity, given the scales of the Meso-NH output, are captured reasonably well (Meso- 


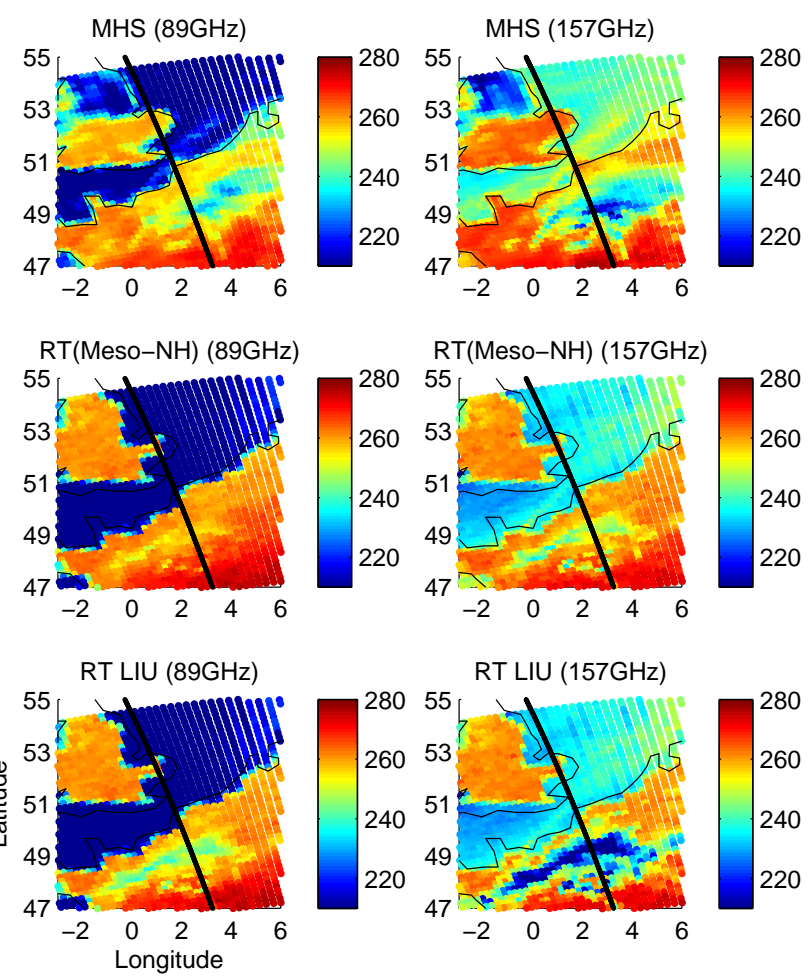

Figure 8. MHS observations at 89 and $157 \mathrm{GHz}$ (top panels), as compared to its radiative transfer simulations using the baseline configuration (i.e. assumptions intrinsic to the microphysical scheme of Meso-NH; middle panels), and the Meso-NH intrinsic scheme together with the Liu (2004) approximation and multiplying the snow quantities systematically by 1.25 (bottom panels). The solid black line illustrates the CloudSat track.

$\mathrm{NH}$ has $5 \mathrm{~km}$ resolution, while the nadir CloudSat footprint has $1.4 \mathrm{~km}$ resolution). It is evident, however, that such microphysical assumptions also underestimate the backscattering properties, for the same reason as with passive simulations. Replacing the Meso-NH parametrization of mass by a fixed density of $0.1 \mathrm{~g} \mathrm{~cm}^{-3}$ is done as for passive simulations (simulation D only yields a slight improvement - not shown). Figure $7 \mathrm{~b}$ shows fixed-density horizontally aligned spheroids of aspect ratio 1.6 (simulation $\mathrm{E}$ in Table 2). Only a slight improvement is observed with higher reflectivities where the Meso-NH total ice content is higher and closer to retrieved products (mainly around 2.4 and east of $3^{\circ} \mathrm{W}$ - see Fig. 4). The approximation by Liu (2004) is also tested for the active response for perfect spheres (not shown) and in Fig. 7c for horizontally aligned spheroids of aspect ratio 1.6 (simulation $\mathrm{H}$ in Table 2). The reflectivity is still systematically underestimated, regardless of the hypothesis.

Based on conclusions drawn from Fig. 4 and the analysis of passive simulations, Fig. 7 (right column) presents the same active simulations as above, but multiplying the snow quantities systematically by 1.25 to account for the underestimation of the Meso-NH IWP. Note that Fig. 4 shows that
Meso-NH model outputs west of $2.3^{\circ}$ significantly underestimate the integrated frozen phase content, which coincides with a large difference in the simulated versus observed radar reflectivity in the upper part of the cloud, which is composed of smaller pristine ice particles. The ability of models to accurately describe the conversion mechanisms - e.g. from pristine ice crystals to aggregated snow or the interaction of cloud ice with the liquid phase - is still poorly understood.

For the rest of the CloudSat track analysed, however, it is fair to assume that the Meso-NH output are reasonable, and that despite uncertainties, the underlining complexities arise from determining accurate scattering properties. Focusing on the 1.25 multiplication factor derived from the analysis of Fig. 4, the comparisons with the observations are not better in the case of the Meso-NH hypothesis, but they are significantly improved with the approximation by Liu (2004). As previously discussed, this same configuration was shown to work well with the passive simulations. This is very encouraging, and shows that we can reasonably simulate both passive and active observations, with careful and consistent assumptions about the parameters that determine the scattering properties. Figure 8 shows the simulations for those MHS channels most sensitive to the frozen phase using these last assumptions (the approximation by Liu (2004), and multiplying the snow quantities systematically by 1.25 ), as compared to the previously introduced observations and simulations. The new simulations enhance scattering. Future work is planned in order to incorporate publicly available databases of DDA from Liu (2004) directly, in order to avoid the approximation used in this study and developed by the same author. A number of studies have started the complex task of using DDA databases directly, such as Geer and Baordo (2014) who implemented with success the original DDA tables provided by Liu (2004) and others in their calculations.

\section{Conclusions}

Microwave passive and active radiative transfer simulations are presented for a specific snowfall mid-latitude scene, using outputs from the Meso-NH mesoscale cloud model and compared to the corresponding microwave observations available from MHS and CloudSat. The sensitivity of radiative transfer simulations to the microphysical characteristics of the frozen particles (size, density, dielectric properties) is the focus of this study.

The radiative transfer simulations were performed by coupling ARTS and its recently incorporated active simulator module, to the mesoscale cloud model Meso-NH. Performing a comparison of simulations and observations over a large range of frequencies and exploiting the passive/active synergy is a challenging but useful task because it imposes strong constraints on the assumptions made to simulate the observations. 
Disregarding the detailed spatial structures which would make this task unrealistic, an overall agreement is obtained between the simulated and the observed brightness temperatures (passive) and radar reflectivities (active). The largescale dynamical structure of the cloud system is reasonably captured by Meso-NH. However, comparisons between the radiative transfer simulations and the available observations show a misrepresentation in the areas of strong scattering. From our sensitivity analysis, the failure to reproduce the observed strong scattering signals arises from the interpretation of Meso-NH microphysical parametrizations of snow particles in the radiative transfer simulations.

Nonetheless, both passive and active radiative transfer simulations showed very encouraging results, as we can reasonably simulate available observations from consistent assumptions on the parameters that determine the scattering properties, especially with the Liu (2004) approximation. The Liu (2004) approximation provides a frequencydependent effective density for snow particles that results in more realistic scattering properties. Hence, it is important to conclude that the microphysical assumptions in the Meso$\mathrm{NH}$ scheme are realistic, provided that they are well interpreted in the scattering calculation. This is an important step towards building a robust data set of simulated measurements to train a statistically base retrieval scheme.

Acknowledgements. The ARTS community is appreciated for providing, developing and maintaining such an open source software. The authors would like to also thank the reviewers for their careful reading of the paper and their constructive suggestions.

Edited by: J. Joiner

\section{References}

Aires, F., Prigent, C., Bernardo, F., Jiménez, C., Saunders, R., and Brunel, P.: A Tool to Estimate Land-Surface Emissivities at Microwave frequencies (TELSEM) for use in numerical weather prediction, Q. J. Roy. Meteor. Soc., 137, 690-699, 2011.

Austin, R. T., Heymsfield, A. J., and Stephens, G. L.: Retrieval of ice cloud microphysical parameters using the CloudSat millimeter-wave radar and temperature, J. Geophys. Res.-Atmos. (1984-2012), 114, D00A23, doi:10.1029/2008JD010049, 2009.

Battaglia, A., Haynes, J., L'Ecuyer, T., and Simmer, C.: Identifying multiple-scattering-affected profiles in CloudSat observations over the oceans, J. Geophys. Res.-Atmos. (1984-2012), 113, D00A17, doi:10.1029/2008JD009960, 2008.

Bennartz, R. and Bauer, P.: Sensitivity of microwave radiances at 85-183 GHz to precipitating ice particles, Radio Sci., 38, 8075, 2003.

Bonsignori, R.: The Microwave Humidity Sounder (MHS): in-orbit performance assessment, in: Remote Sensing, International Society for Optics and Photonics, 67440A, 2007.

Bruggeman, D. A. G.: Berechnung verschiedener physikalischer Konstanten von heterogenen Substanzen. I. Dielektrizitätskon- stanten und Leitfähigkeiten der Mischkörper aus isotropen Substanzen, Annalen der Physik, 416, 636-664, 1935.

Buehler, S. A., Courcoux, N., and John, V. O.: Radiative transfer calculations for a passive microwave satellite sensor: Comparing a fast model and a line-by-line model, J. Geophys. Res., 111, D20304, 2006.

Chaboureau, J.-P., Cammas, J.-P., Mascart, P., Pinty, J.-P., Claud, C., Roca, R., and Morcrette, J.-J.: Evaluation of a cloud system lifecycle simulated by the Meso-NH model during FASTEX using METEOSAT radiances and TOVS-3I cloud retrievals, Q. J. Roy. Meteor. Soc., 126, 1735-1750, 2000.

Chaboureau, J.-P., Söhne, N., Pinty, J.-P., Meirold-Mautner, I., Defer, E., Prigent, C., Pardo, J. R., Mech, M., and Crewell, S.: A Midlatitude Precipitating Cloud Database Validated with Satellite Observations, J. Appl. Meteorol. Clim., 47, 1337, doi:10.1175/2007JAMC1731.1, 2008.

Davis, C. P., Evans, K. F., Buehler, S. A., Wu, D. L., and Pumphrey, H. C.: 3-D polarised simulations of space-borne passive $\mathrm{mm} / \mathrm{sub}$ mm midlatitude cirrus observations: a case study, Atmos. Chem. Phys., 7, 4149-4158, doi:10.5194/acp-7-4149-2007, 2007.

Delanoë, J. and Hogan, R. J.: A variational scheme for retrieving ice cloud properties from combined radar, lidar, and infrared radiometer, J. Geophys. Res.-Atmos. (1984-2012), 113, D07204, doi:10.1029/2007JD009000, 2008.

Delanoë, J. and Hogan, R. J.: Combined CloudSat-CALIPSOMODIS retrievals of the properties of ice clouds, J. Geophys. Res.-Atmos. (1984-2012), 115, D00H29, doi:10.1029/2009JD012346, 2010.

Dungey, C. and Bohren: Backscattering by nonspherical hydrometeors as calculated by the coupled-dipole method- An application in radar meteorology, J. Atmos. Ocean. Tech., 10, 526-532, 1993.

Eliasson, S., Buehler, S. A., Milz, M., Eriksson, P., and John, V. O.: Assessing observed and modelled spatial distributions of ice water path using satellite data, Atmos. Chem. Phys., 11, 375391, doi:10.5194/acp-11-375-2011, 2011.

Eriksson, P., Buehler, S., Davis, C., Emde, C., and Lemke, O.: ARTS, the atmospheric radiative transfer simulator, version 2, J. Quant. Spectrosc. Ra., 112, 1551-1558, 2011.

Garnett, J. M.: Colours in metal glasses, in metallic films, and in metallic solutions. II, Philosophical Transactions of the Royal Society of London. Series A, Containing Papers of a Mathematical or Physical Character, 237-288, 1906.

Geer, A. J. and Baordo, F.: Improved scattering radiative transfer for frozen hydrometeors at microwave frequencies, Atmos. Meas. Tech., 7, 1839-1860, doi:10.5194/amt-7-1839-2014, 2014.

Hanesch, M.: Fall velocity and shape of snowflakes, PhD. thesis, Swiss Federal Institute of Technology, 2009.

Haynes, J., Luo, Z., Stephens, G., Marchand, R., and BodasSalcedo, A.: A multipurpose radar simulation package: QuickBeam, B. Am. Meteorol. Soc., 88, 1723-1727, 2007.

Hogan, R. J., Tian, L., Brown, P. R. A., Westbrook, C. D., Heymsfield, A. J., and Eastment, J. D.: Radar Scattering from Ice Aggregates Using the Horizontally Aligned Oblate Spheroid Approximation, J. Appl. Meteorol. Clim., 51, 655-671, 2012.

Johnson, B. T., Petty, G. W., and Skofronick-Jackson, G.: Microwave Properties of Ice-Phase Hydrometeors for Radar and Radiometers: Sensitivity to Model Assumptions, J. Appl. Meteorol. Clim., 51, 2152-2171, 2012. 
Katsumata, M., Uyeda, H., Iwanami, K., and Liu, G.: The Response of 36- and 89-GHz Microwave Channels to Convective Snow Clouds over Ocean: Observation and Modeling, J. Appl. Meteorol., 39, 2322-2335, 2000.

Kim, M.-J.: Single scattering parameters of randomly oriented snow particles at microwave frequencies, J. Geophys. Res.-Atmos., 111, D14201, doi:10.1029/2005JD006892, 2006.

Kneifel, S., Redl, S., Orlandi, E., Lohnert, U., Cadeddu, M. P., Turner, D. D., and Chen, M.-T.,: Absorption Properties of Supercooled Liquid Water between 31 and $225 \mathrm{GHz}$ : Evaluation of Absorption Models Using Ground-based Observations, J. Appl. Meteorol. Clim., 53, 1028-1045, doi:10.1175/JAMC-D-13-0214.1, 2014.

Korolev, A. and Isaac, G.: Roundness and Aspect Ratio of Particles in Ice Clouds, J. Atmos. Sci., 60, 1795-1808, 2003.

Kulie, M. S., Bennartz, R., Greenwald, T. J., Chen, Y., and Weng, F.: Uncertainties in Microwave Properties of Frozen Precipitation: Implications for Remote Sensing and Data Assimilation, J. Atmos. Sci., 67, 3471-3487, 2010.

Lafore, J. P., Stein, J., Asencio, N., Bougeault, P., Ducrocq, V., Duron, J., Fischer, C., Héreil, P., Mascart, P., Masson, V., Pinty, J. P., Redelsperger, J. L., Richard, E., and Vilà-Guerau de Arellano, J.: The Meso-NH Atmospheric Simulation System. Part I: adiabatic formulation and control simulations, Ann. Geophys., 16, 90-109, doi:10.1007/s00585-997-0090-6, 1998.

Liebe, H. J., Hufford, G. A., and Manabe, T.: A model for the complex permittivity of water at frequencies below $1 \mathrm{THz}$, Int. J. Infrared. Milli., 12, 659-675, 1991.

Liu, G.: Approximation of single scattering properties of ice and snow particles for high microwave frequencies, J. Atmos. Sci., 61, 2441-2456, 2004.

Liu, Q., Weng, F., and English, S.: An Improved Fast Microwave Water Emissivity Model, Geoscience and Remote Sensing, IEEE Transactions on, 49, 1238-1250, 2011.

Mace, G.: Level 2 GEOPROF product process description and interface control document algorithm version 5.3, NASA Jet Propulsion Laboratory, 2007.

Matrosov, S. Y., Heymsfield, A. J., and Wang, Z.: Dual-frequency radar ratio of nonspherical atmospheric hydrometeors, Geophys. Res.-Lett., 32, L13816, doi:10.1029/2005GL023210, 2005.

Mätzler, C.: Thermal microwave radiation: applications for remote sensing, vol. 52, Iet, 2006.

Meirold-Mautner, I., Prigent, C., Defer, E., Pardo, J. R., Chaboureau, J.-P., Pinty, J.-P., Mech, M., and Crewell, S.: Radiative Transfer Simulations Using Mesoscale Cloud Model Outputs: Comparisons with Passive Microwave and Infrared Satellite Observations for Midlatitudes, J. Atmos. Sci., 64, 1550-1568, 2007.

Melsheimer, C., Verdes, C., Buehler, S. A., Emde, C., Eriksson, P., Feist, D. G., Ichizawa, S., John, V. O., Kasai, Y., Kopp, G., Koulev, N., Kuhn, T., Lemke, O., Ochiai, S., Schreier, F., Sreerekha, T. R., Suzuki, M., Takahashi, C., Tsujimaru, S., and Urban, J.: Intercomparison of general purpose clear sky atmospheric radiative transfer models for the millimeter/submillimeter spectral range, Radio Sci., 40, RS1007, doi:10.1029/2004RS003110, 2005.
Mishchenko, M. I.: Calculation of the amplitude matrix for a nonspherical particle in a fixed orientation, Appl. Optics, 39, 10261031, 2000.

Noh, Y.-J., Liu, G., Seo, E.-K., Wang, J. R., and Aonashi, K.: Development of a snowfall retrieval algorithm at high microwave frequencies, J. Geophys. Res.-Atmos., 111, D22216, doi:10.1029/2005JD006826, 2006.

Nowell, H., Liu, G., and Honeyager, R.: Modeling the microwave single-scattering properties of aggregate snowflakes, J. Geophys. Res.-Atmos., 118, 7873-7885, 2013.

Pinty, J. and Jabouille, P.: A mixed-phase cloud parameterization for use in a mesoscale non-hydrostatic model: simulations of a squall line and of orographic precipitations, in: Conf. on Cloud Physics, 217-220, 1998.

Purcell, E. M. and Pennypacker, C. R.: Scattering and absorption of light by nonspherical dielectric grains, Astrophys. J., 186, 705714, 1973.

Saunders, R., Rayer, P., Brunel, P., von Engeln, A., Bormann, N., Strow, L., Hannon, S., Heilliette, S., Liu, X., Miskolczi, F., Han, Y., Masiello, G., Moncet, J.-L., Uymin, G., Sherlock, V., and Turner, D. S.: A comparison of radiative transfer models for simulating Atmospheric Infrared Sounder (AIRS) radiances, J. Geophys. Res.-Atmos., 112, D01S90, doi:10.1029/2006JD007088, 2007.

Skofronick-Jackson, G. and Johnson, B.: Thresholds of detection for falling snow from satellite-borne active and passive sensors, in: Geoscience and Remote Sensing Symposium (IGARSS), 2011 IEEE International, 2637-2640, 2011.

Skofronick-Jackson, G., Gasiewski, A. J., and Wang, J. R.: Influence of microphysical cloud parameterizations on microwave brightness temperatures, IEEE T. Geosci. Remote., 40, 187-196, 2002.

Stephens, G. L., Vane, D. G., Boain, R. J., Mace, G. G., Sassen, K., Wang, Z., Illingworth, A. J., O'Connor, E. J., Rossow, W. B., Durden, S. L., Miller, S. D., Austin, R. T., Benedetti, A., Mitrescu, C., and CloudSat Science Team, T.: THE CLOUDSAT MISSION AND THE A-TRAIN, B. Am. Meteorol. Soc., 83, 1771-1790, 2002.

Thompson, G., Rasmussen, R. M., and Manning, K.: Explicit forecasts of winter precipitation using an improved bulk microphysics scheme. Part I: Description and sensitivity analysis, Mon. Weather Rev., 132, 519-542, 2004.

Waliser, D. E., Li, J.-L. F., Woods, C. P., Austin, R. T., Bacmeister, J., Chern, J., Del Genio, A., Jiang, J. H., Kuang, Z., Meng, H., Minnis, P., Platnick, S., Rossow, W. B., Stephens, G. L., SunMack, S., Tao, W.-K., Tompkins, A. M., Vane, D. G., Walker, C., and $\mathrm{Wu}, \mathrm{D} .:$ Cloud ice: A climate model challenge with signs and expectations of progress, J. Geophys. Res.-Atmos., 114, D00A21, doi:10.1029/2008JD010015, 2009.

Wiedner, M., Prigent, C., Pardo, J. R., Nuissier, O., Chaboureau, J.-P., Pinty, J.-P., and Mascart, P.: Modeling of passive microwave responses in convective situations using output from mesoscale models: Comparison with TRMM/TMI satellite observations, J. Geophys. Res.-Atmos. (1984-2012), 109, D06214, doi:10.1029/2003JD004280, 2004. 